\title{
ANÁLISE DE POLÍTICAS PÚBLICAS: uma breve revisão de aspectos metodológicos para formulação de políticas
}

\author{
R. B. Estevão ${ }^{1}$, M. D. M. Ferreira² \\ 1,2Programa de Pós-Graduação em Políticas Públicas - UFPI \\ renildoe@yahoo.com.br ${ }^{1}$ \\ Submetido 02/01/2018 - Aceito 07/08/2018 \\ DOI: $10.15628 /$ holos. 2018.6818
}

\section{RESUMO}

É objetivo deste artigo apresentar uma reflexão acerca da Análise de Política Pública. Para tanto, recorre-se à literatura relativa à formulação de política pública e sua agenda, bem como do processo de tomada de decisão. Inicialmente, apresenta-se uma ideia simplificada de sistema político, com suas demandas, decisões e ações, utilizando-se como cenário, o modelo sistêmico. Em seguida, abordam-se as influências que as relações entre Estado e sociedade trazem para as políticas públicas e as visões do Estado que buscam explicar essas relações. No ponto seguinte, conceitua-se análise de políticas, bem como esclarecem-se seus objetivos. Num quarto momento, são expostos os modelos de tomada de decisão relevantes à formulação da política. Por fim, apresenta-se o papel das organizações na formulação da política. Assim, foi possível explorar aspectos essenciais para se verificar o processo de construção da política pública e por que determinada política entra na agenda pública, destacando-se "um estudo da elaboração das políticas", onde as atenções se voltam à fase da formulação da política pública.

PALAVRAS-CHAVE: Análise de Políticas Públicas, Formulação de Políticas, Agenda Pública, Tomada de Decisão.

\section{PUBLIC POLICY ANALYSIS: a brief review of methodological aspects for policy formulation}

\begin{abstract}
It is the objective of this article to present a reflection on Public Policy Analysis. In order to do so, we use the literature on the formulation of public policy and its agenda, as well as the decision-making process. Initially, it presents a simplified idea of the political system, with its demands, decisions and actions, using as a scenario, the systemic model. Next, we address the influences that the relations between State and society bring to public policies and the visions of the State that seek to explain these relations. In the following section, policy analysis is conceptualized, as well as clarifying its
\end{abstract}

objectives. At the fourth moment, the decision-making models relevant to the formulation of the policy are exposed. Finally, the role of organizations in the formulation of policy is presented. Thus, it was possible to explore aspects essential to verify the process of public policy-making and why a policy enters the public agenda, highlighting "a study of policy-making", where attention is focused on the policy formulation phase public.

KEYWORDS: Analysis of Public Policies, Policymaking, Public Agenda, Decision Making. 


\section{INTRODUÇÃO}

As sociedades modernas têm, como principal característica, relações complexas entre seus membros e suas instituições, logo, diferentes ideias, valores, interesses e anseios surgem como geradores de conflitos. A política surge como um meio capaz de administrar toda essa complexidade e fazer, por meio de decisões e ações, a sociedade sobreviver e progredir. Mas o que é a política?

Várias são as definições atribuídas ao termo política, fato que sugere, segundo Ham e Hill (1993), uma dificuldade em tratá-la como um fenômeno muito específico e concreto. Mas, após leitura de suas discussões sobre o tema, fica-se com a ideia de que a política representa um curso de ação ou inação, ou uma teia de complexas decisões. Isso, segundo eles, implica aspectos, como: (i) a existência de uma rede de decisões complexas e que, tomadas em conjunto, definem, de certa forma, o que é política; (ii) as políticas se modificam com o passar dos tempos, o que torna difícil o seu término; (iii) as não-decisões também devem ser analisadas quando do estudo de políticas.

Nesse conjunto de decisões e ações complexas que resultam da atividade política, tem-se as políticas públicas, revestidas de autoridade soberana do poder público no que concerne à alocação de recursos.

A Análise de Política, por sua vez, coloca em pauta tanto a política quanto a política pública, visto que, por um lado, procura conhecer as ações do governo, descrevendo-as, e, por outro, analisa e prescreve as políticas públicas. Eis a esperança na Análise de Política como forma de atenuar problemas sociais por meio do aperfeiçoamento da formulação e da implementação das políticas públicas.

Contudo, existem diferentes tipos de Análises de Política, e a escolha dependerá do trabalho que o analista irá desenvolver. Ham e Hill (1993), recorrendo a uma análise de Hogwood e Gunn (1981), apresentam sete variedades possíveis de Análise de Política que podem ser escolhidas segundo variáveis, como os aspectos ideológicos, os objetivos ou o ambiente político.

Os tipos de Análise, segundo Ham e Hill (1993), são: (i) estudo do conteúdo das políticas: o analista procura investigar como uma determinada política surgiu, como foi implementada e os resultados obtidos; (ii) estudo da elaboração das políticas: dirige-se a atenção para questões inerentes às influências na formulação de políticas; (iii) estudo dos resultados das políticas: buscase explicar por que gastos e serviços variam em diferentes áreas, tentando compreender as políticas em termos de fatores sociais, econômicos, tecnológicos e outros; (iv) avaliação de políticas: procuram-se identificar os impactos advindos da política sobre a população; (v) informação para elaboração de políticas: trata de organizar dados para auxiliar os fazedores de política na tomada de decisões; (vi) defesa do processo de elaboração da política: os estudos são voltados para melhorar os processos de elaboração de políticas e a máquina do governo; (vii) defesa de políticas: o analista defende a adoção de ideias e opções no processo de elaboração de políticas. 
No entanto, para que a Análise de Política possa atingir ou se aproximar de seus objetivos, se faz necessária uma multiplicidade de preocupações em diferentes níveis de análise, seja diante do funcionamento da estrutura administrativa estatal, seja mediante seus processos decisórios ou da relação entre o Estado e a sociedade.

Assim, neste artigo, se realiza um estudo inerente a esses níveis, onde se procurou estabelecer uma relação entre os mesmos, preocupando-se, primordialmente, com o processo de elaboração de políticas. Essa tarefa foi realizada em seis momentos. Inicialmente, apresentou-se ideia simplificada de sistema político, com suas demandas, decisões e ações, utilizando, como cenário, o modelo sistêmico. Em seguida, abordou-se as influências que as relações entre Estado e sociedade trazem para as políticas públicas. Num terceiro momento, conceituou-se Análise de Política, bem como se esclareceu seus objetivos. O ponto seguinte, ocupou-se com os corpos teóricos que buscam explicar as influências do Estado e dos fatores sociais no desenvolvimento de políticas públicas. No quarto momento, foram apresentados os modelos de tomada de decisão relevantes à formulação da política. Por fim, encerrou-se apresentando o papel das organizações na formulação da política.

Por meio deste trabalho, objetiva-se, portanto, apresentar alguns conceitos e categorias de Análise de Políticas Públicas, trazendo contribuições de autores, como forma de auxílio metodológico para que um Analista de Políticas possa melhor compreender o processo de elaboração de políticas públicas.

\section{SISTEMA POLÍTICO}

Como esclarecem Ham e Hill (1993), citando Wildavsky (1979), a política pública não se refere apenas ao processo de elaboração da política (tomada de decisões), posto que, ao tempo em que é processo, também é produto deste.

Dessa forma, é possível discutir, mesmo com certas limitações, as complexidades do sistema político e seu processo de tomada de decisões, utilizando-se do enfoque sistêmico de Easton (1953, 1965a; 1965b apud Ham \& Hill, 1993), o qual cria a ideia de um "Sistema Político", conforme a figura abaixo.

Figura 1: Modelo simplificado do sistema político

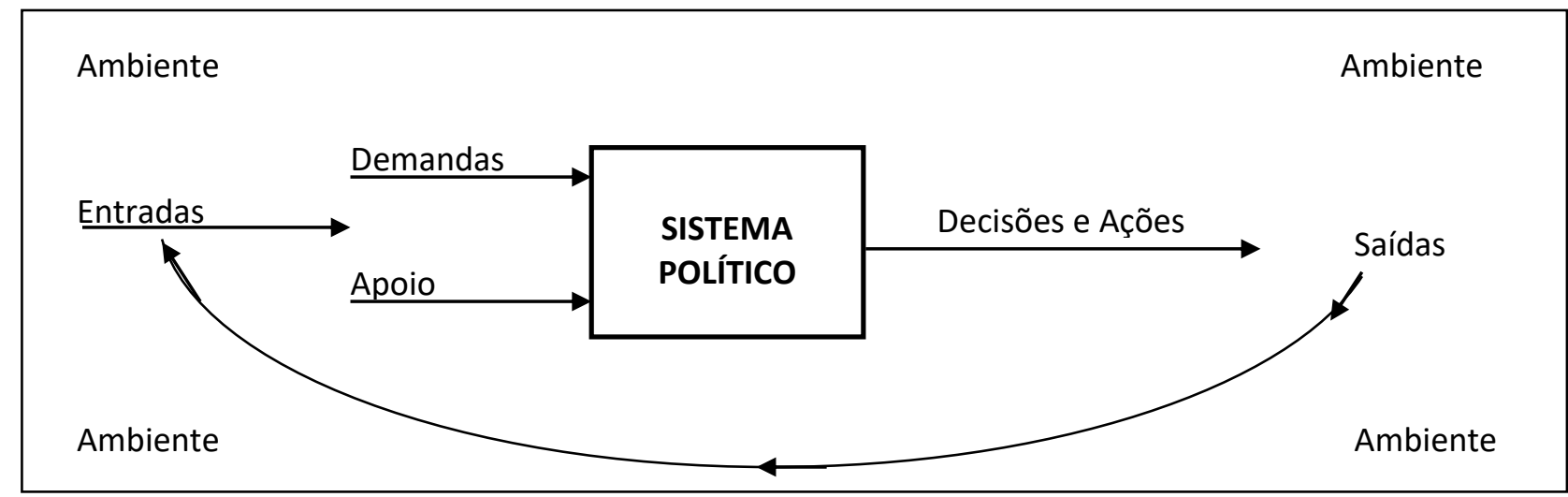

Fonte: Easton (1965a), citado por Ham e Hill (1993, p. 29). 
O "Sistema Político" apresentado acima é composto por inputs (entradas ou perguntas) e outputs (saídas ou respostas). As entradas estariam representadas por demandas e apoio. As demandas envolveriam ações de indivíduos e grupos na busca de alocação de recursos para atender seus interesses. Como exemplo de demandas, podem-se citar as

[...] reivindicações de bens e serviços, como saúde, educação, estradas, transportes, segurança pública, normas de higiene e controle de produtos alimentícios, previdência social, etc. Podem ser, ainda, demandas de participação no sistema político, como reconhecimento do direito de voto dos analfabetos, acesso a cargos públicos para estrangeiros, organização de associações políticas, direitos de greve, etc. Ou ainda, demandas de controle da corrupção, de preservação ambiental, de informação política, de estabelecimento de normas para o comportamento dos agentes públicos e privados, etc. (Rua, 1997, p. 2).

Quanto ao apoio, englobam-se, conforme o enfoque sistêmico, ações como obediência à lei e pagamento de taxas ou ainda

[...] atos de participação política, como o simples ato de votar e apoiar um partido político, o respeito à autoridade dos governantes e aos símbolos nacionais; a disposição para pagar tributos e para prestar serviços, como por exemplo o serviço militar, etc. Mas podem ser também atos mais fortes, como o envolvimento na implementação de determinados programas governamentais, a participação em manifestações públicas, etc. (Rua, 1997, p. 2).

Após processadas no "Sistema Político", as entradas resultariam nas respostas em forma de decisões políticas ou da própria política pública. Haveria ainda uma retroalimentação do sistema com essas saídas, as quais gerariam novas entradas, como pode ser observado por meio da Figura 1, acima.

O modelo sistêmico, segundo Ham e Hill (1993), apresenta vantagens, como a conceitualização de fenômenos políticos complexos, apresentando avanço em relação às análises mais tradicionais da ciência política e da administração pública. Outra importância, identificada pelos autores, refere-se ao fato de o modelo decompor "o processo de elaboração de políticas em uma série de estágios diferentes, de forma que cada um dos quais possa ser analisado mais detalhadamente" (Ham \& Hill, 1993, p. 30).

Todavia, esses autores descrevem algumas desvantagens incorporadas pelo modelo sistêmico. Dentre elas, destacam-se as seguintes:

I - Existe no sistema uma redução lógica dos processos em relação ao mundo prático da elaboração de políticas, tendo em vista que outras variáveis (manipulação de linguagem, criação de crises, imposição de agendas para autoridades ou mesmo simulação de políticas) afetam a simples conversão de demandas e apoios em saídas;

II - O sistema não toma por base a dinâmica na tomada de decisões (caixa preta), desconsiderando demandas e apoios externos, tal como atividades políticas entre níveis de governo (central e local) e diferentes departamentos de mesmo nível;

III - É preciso que o sistema dê mais atenção às relações entre as entidades de governo, visto que se sujeitam a ajustes contínuos, na medida em que obrigações e orçamentos são alterados, fato que pode modificar os resultados específicos almejados. 
Não obstante as desvantagens apresentadas, um dos méritos do modelo sistêmico, para Ham e Hill (1993), deve-se à atenção dada ao relacionamento entre sistemas políticos e seu meioambiente (urbanização, renda per capita, nível educacional etc.). Observa-se, assim, que o modelo considera importante a inter-relação entre Estado, política, economia e sociedade.

Como acrescentam Ham e Hill (1993, p. 34-35), citando Minoque (1983), qualquer teoria que queira explicar satisfatoriamente o que é política pública, deve explicar também as interrelações entre Estado, política e sociedade, tendo em vista os efeitos provocados pelas políticas públicas sobre a economia e a comunidade. É o que se aborda a seguir.

\section{ESTADO, SOCIEDADE CIVIL E POLÍTICAS PÚBLICAS}

É importante frisar, inicialmente, que a política pública não se refere apenas às questões que envolvem a sua formulação, ou seja, a partir dos desdobramentos da aplicação dos recursos, dos seus aspectos jurídicos, da legitimidade ou apenas como atributo do Estado. Mas deve-se debater também a sua historicidade, o surgimento das ideias e dos atores envolvidos. Afinal, é da relação entre atores ${ }^{1}$, como o Estado, classes sociais e a sociedade civil, como explica Boneti (2007), que surgem os agentes capazes de definir a política pública. Além disso, como bem observa Dias e Matos (2012), uma cooperação entre os atores envolvidos, de forma participativa e dialógica é essencial no processo de implementação de uma dada política pública.

Essa relação entre Estado, classes sociais e a sociedade civil se deu, segundo Battini e Costa (2007), a partir do século XX. Nesse período, conforme os autores, o Estado deixou de ser entendido apenas como instrumento de dominação capitalista e passou a ser visto como o resultado da organização política de uma sociedade de classes e seus conflitos de interesses. Nesta seara, entram as políticas públicas, marcadas por esses conflitos e disputas de interesses, onde se materializam o poder do Estado, paralelo ao pacto político firmado na sociedade (Battini \& Costa, 2007).

As políticas públicas são, assim, instrumentos para efetivar os direitos do cidadão, intermediando o pacto entre o Estado e a sociedade. Não há, entretanto, certeza de que os direitos sociais sejam efetivados, pois tudo irá depender da maior ou menor representatividade que cada segmento representado possui.

Adicionalmente, como ressalta Boneti (2007), a definição das políticas públicas também é determinada pelos interesses das elites globais, a exemplo do Fundo Monetário Internacional e da Organização Mundial do Comércio. Esses órgãos interferem na elaboração das políticas públicas dos países periféricos, prevalecendo-se do poder econômico, por meio de empréstimos, fazendoos adotar modelos homogêneos de desenvolvimento econômico e social no atendimento aos interesses da elite.

As elites, portanto, se utilizam de diferentes estratégias para ganhar poderes e, assim, interferirem no caráter e na operacionalização das políticas públicas. A própria ideia de centro e periferia reforça o caráter de verdade assumido pelo setor economicamente dominante. Logo,

\footnotetext{
${ }^{1}$ São aqueles cujos interesses serão afetados, positiva ou negativamente, pelas decisões e ações (RUA, 2013, P. 12).
} 
tem-se o centro com mais condições quanto aos aspectos tecnológicos e de desenvolvimento social, impondo um modelo elitizado como padrão de vida e da verdade, sendo, tal concepção, incorporada pelos setores pobres no sentido de tentar atingir o mesmo modelo.

O modelo referencial para igualar as diferenças, adotado pela estrutura de poder atual, é a tecnologia, conforme Boneti (2007). Ou seja, o que passa a prevalecer é a regra da competência tecnológica, com vistas à adoção de políticas públicas de inovação tecnológica, como sendo as de maior impacto social, o que vem a beneficiar uns segmentos em detrimento de outros. A partir dessas regras - regras de exclusão -, selecionam-se certas questões da agenda política, que passam a receber mais atenção em detrimento da omissão de outras.

O progresso tecnológico começa, então, a ser utilizado como referencial de desenvolvimento e um fator ideológico da concepção de que esse seria o caminho para o bemestar social. Entretanto, as políticas de desenvolvimento tecnológico focam o benefício de segmentos sociais que dispõem de recursos econômicos e tecnológicos, o que deixa outros fora da agenda política. $O$ problema gerado por esse modelo padronizado pelas elites refere-se à questão da igualdade, o que, na concepção de Boneti (2007), não se estabelece pela maioria, mas toma por base o padrão imposto pela classe dominante da sociedade capitalista e gera desigualdade.

Observa-se, assim, que representantes da sociedade civil organizada, como ONGs e movimentos sociais, assumem papel fundamental no sentido de impedir que as práticas sociais impostas pelas classes dominantes em conflito com os interesses da sociedade não se conformem por meio das políticas públicas. Ademais, os atores locais são importantes no processo de elaboração e operacionalização das políticas públicas para que não sejam executadas apenas em função do interesse de grupos dominantes.

Ressalta-se que, durante o ciclo da política pública, ocorre o envolvimento de diferentes pessoas e instituições, cada qual inserindo um pouco de seus interesses particulares quando da implementação da política.

Portanto, a política pública, desde sua elaboração até a sua operacionalização, segue um ciclo inerte num contexto social, onde há conflitos e necessidades a serem harmonizadas. $\mathrm{O}$ que, segundo a abordagem de Boneti (2007), é o resultado da dinâmica de jogo de forças que se dá no âmbito das relações de poder, com a participação de grupos políticos, econômicos, classes sociais e demais organizações da sociedade civil.

Levando-se em consideração esses aspectos, entender as visões que modelam as relações entre Estado e sociedade, torna-se mais uma etapa essencial à análise de uma política pública. Portanto, abordaremos, a seguir, as visões pluralista, marxista, elitista e corporativista.

\subsection{Visões do Estado}

Ham e Hill (1993) apontam quatro corpos teóricos que buscam explicar as influências do Estado e dos fatores sociais no desenvolvimento de políticas públicas: são as visões pluralista, marxista, elitista e corporativista. 
A teoria pluralista, segundo Dahl (1961), citado por Ham e Hill (1993, p. 47), "aponta que as fontes de poder estão distribuídas de forma desigual, mas de forma ampla entre indivíduos e grupos, dentro da sociedade". Logo, para essa teoria, nenhum indivíduo ou grupo é destituído de poder, mas sua entrada na agenda política dependerá de seus recursos e dos seus grupos de pressão. Aliás, a representação das ideias por meio de grupos de pressão, segundo Ham e Hill (1993), pode mostrar-se como umas das faces da democracia e desempenhar o papel de representação de interesses específicos.

Esse ponto de vista, no contexto britânico, foi relatado por Richardson e Jordan (1979 apud Ham \& Hill, 1993) que afirmam que, na Inglaterra, determinadas políticas públicas entram na agenda por influências de grupos de pressão que negociam com as agências do governo. Nos Estados Unidos, como explicam Ham e Hill (1993), esses grupos também são vistos como centrais na teoria pluralista. Além disso, acrescentam os autores, no Estado de bem-estar, de forma similar, o governo passou a consultar e negociar com grupos organizados (de pressão) no intuito de obter apoio e voto.

Quanto à teoria elitista, contrapõe-se à pluralista e, no Estado moderno, explicam Ham e Hill (1993), está ligada à centralização de poder nas mãos de uma elite política (burocratas, militares, aristocratas e empresários). Dessa forma, na visão de Mosca (1939 apud Ham \& Hill, 1993, p. 50-51), existe

[...] uma classe que governa e outra que é governada. A primeira classe, sempre a menos numerosa, executa todas as funções políticas, monopoliza o poder e goza das vantagens que o poder traz, enquanto que a segunda, a classe mais numerosa, é dirigida e controlada pela primeira de uma forma que é ora mais ou menos legal, ora mais ou menos arbitrária e violenta.

Não obstante as instituições serem geridas por grupos minoritários, é possível a compatibilidade desse modelo com a democracia pluralista. Isto porque, segundo Ham e Hill (1993), a competição entre líderes de partidos políticos e elites de grupos de pressão, durante as eleições, representaria a forma sob a qual a democracia funcionaria no Estado moderno.

Já na visão marxista, o Estado representa o meio para a domínio do poder de determinada classe, notadamente a burguesa. Ou seja, o Estado serve de instrumento para realização dos interesses dessa classe. Miliband (1969 apud Ham \& Hill, 1993) cita três razões principais do porquê desse domínio: (i) a semelhança em termos de origem social entre a burguesia e a elite estatal; (ii) o poder que a burguesia tem como grupo de pressão, seja por intermédio de contatos pessoais, redes de influência ou mediante a defesa de interesse particulares; (iii) a limitação imposta sobre o Estado pelo poder objetivo do capital. Assim, essa visão dirige sua atenção ao cenário econômico da atividade política.

Finalmente, a quarta visão, a corporativista, segundo Ham e Hill (1993), valendo-se das teorias de Winkler (1976), caracteriza o Estado, frente ao seu relacionamento com o trabalho e o capital, como dominante e independente de classes ou grupos econômicos. O propósito da teoria é colocar o Estado na direção do processo de acumulação de capital, ou seja, ele agiria em prol de determinados grupos conforme sua conveniência. 
Observa-se, portanto, como explica Jessop (1982), citado por Ham e Hill (1993), que o Estado representa um aglomerado de instituições envolvidas em conflito de interesses e que gera impacto sobre cidadãos. Dessa forma, os elementos apresentados anteriormente, mesmo sem grande profundidade, visto sua complexidade, são de grande auxílio no estudo sobre Análise de Política Pública.

\section{CONCEITO E OBJETIVO DA ANÁLISE DE POLÍTICAS PÚBLICAS}

A preocupação com as políticas públicas que dá origem ao surgimento da Análise de Política, segundo Ham e Hill (1993), acentuou-se no início da década de 60, nos Estados Unidos, e teve origem em duas vertentes de interesse:

1. as dificuldades passadas pelos formuladores de política frente à complexidade cada vez maior dos problemas com que se deparavam, levando-os a buscar formas para construção de alternativas e propostas para soluções; e

2. a atenção de pesquisadores acadêmicos em ciências sociais (ciência política, economia, sociologia) que passaram a ter interesse em questões relacionadas às políticas públicas no intuito de aplicarem seu conhecimento à resolução de problemas concretos do setor público.

Simultaneamente, explicam os autores, as agências governamentais começaram a empregar analistas políticos com a missão de utilizar técnicas e práticas visando, por exemplo, analisar custos e benefícios, orçamentos por programas e análise de impacto. Afinal, esse movimento de políticas públicas prometia soluções para as falhas evidentes ocorridas na administração pública.

No Reino Unido, em meados dos anos 70, de acordo com Ham e Hill (1993), programas de ensino universitário, pesquisas, jornais e publicações, tiveram como foco as políticas públicas. No entanto, diferentemente do ocorrido nos Estados Unidos, os analistas de políticas não foram empregados em escala significativa nas agências do governo.

Na década seguinte, nos anos 80 , procuraram-se dispositivos de mercado para resolução de problemas de alocação social, bem como se buscou a aplicação de técnicas de gestão típicas do setor privado para solucionar a ineficácia do setor público. Assim, continuou-se o debate acerca da Análise de Política.

Mas o que é Análise de Política?

Para Rua (2014, p. 20), "uma definição correntemente aceita sugere que a Análise de Política tem como objeto os problemas com que se defrontam os formuladores de política (policy makers) e como objetivo auxiliar o seu equacionamento".

Na visão de Wildavsky (1979), citado por Ham e Hill (1993), não se deve perder tempo na busca de uma definição para Análise de Política, tendo em vista que o termo Análise de Política representa um espectro de variadas atividades, o que dificulta sua definição. Para esse autor, o mais importante é praticá-la em vez de defini-la, ou seja, o analista deve estar engajado em ações, 
pensando sobre problemas e buscando soluções. Tais soluções deveriam se dar, segundo o mesmo autor, mediante um processo baseado na criatividade, imaginação e profissionalismo (Wildavsky, 1979 apud Ham \& Hill, 1993).

Não obstante, Ham e Hill (1993) consideram de grande importância tentar algum esclarecimento de termos e conceitos básicos com relação ao tema.

Análise de Política, para Dye (1976 apud Ham \& Hill, 1993, p. 18), "é descobrir o que os governos fazem, por que o fazem e que diferença isto faz". Tal esclarecimento, coloca a Análise de Política num importante papel de, por um lado, aumentar o conhecimento da ação do governo e, por outro, melhorar a qualidade das políticas públicas. Ou seja, dá uma visão, segundo o autor, de uma atividade tanto prescritiva quanto descritiva. São características que fazem com que importantes autores (Lasswell, 1951; Dror, 1971), citados por Ham e Hill (1993), alimentem grandes esperanças na Análise de Política como forma de melhorar o processo de formulação de políticas e de redução de problemas sociais.

Pode-se mesmo dizer que os resultados das Análises de Políticas não só podem, como devem ser aplicados para dar direcionamento às ideias políticas inerentes à solução de problemas sociais. Afinal, como descrevem Serafim e Dias (2012), a política pública analisada possibilita uma visão descritiva (o que/como é?), explicativa (por que é assim?) e normativa (como deveria ser?).

Para esses autores, ao focar no comportamento dos atores sociais e no processo de formulação da agenda e da política, a Análise de Política busca entender o porquê e para quem aquela política foi elaborada, e não só olhar o conteúdo da política pública em si. Por isso a Análise de Política tem uma central preocupação com o processo de construção da política pública, em especial no que se refere à definição da agenda, podendo determinar as características gerais da política e refletir a priorização de temas e problemas a serem trabalhados por um governo.

Adicionalmente às preocupações elencadas por Serafim e Dias (2012) e que devem fazer parte do estudo numa Análise de Política, outras são descritas por eles, tais como:

- refletir sobre as razões pelas quais a política pública analisada não apresenta características diferentes;

- observar, de forma descritiva, explicativa e normativa, acerca das políticas públicas analisadas, respondendo, respectivamente, às perguntas a respeito de "o que/como é?", "por que é assim?" e "como deveria ser?";

- enfatizar os valores e os interesses dos atores participantes do jogo político, a interação entre eles, a arquitetura de poder, bem como a tomada de decisões, os conflitos e as negociações etc. (Serafim \& Dias, 2012).

Por outro lado, não se deve focar a Análise de Política somente em relação aos problemas já contemplados pela agenda (de discussão) política que irá ser trabalhada pelo governo, sob pena de excluir questões de interesse daqueles grupos desfavorecidos política e socialmente. Ou seja, devem-se considerar tanto as decisões tomadas como as não-tomadas, sendo que estas existem 
efetivamente impedem certas reclamações de se transformarem em questões maduras que exigem decisões (Bachrach \& Baratz, 1963, p. 642 apud Ham \& Hill, 1993, p. 95).

Uma questão importante a ser observada quanto à Análise de Políticas públicas é a relação entre as decisões tomadas, a estrutura institucional e a distribuição de poder no Estado e na sociedade". Assim, o analista precisa, para um melhor estudo do processo de elaboração da política, "levantar algumas das maiores questões sobre o papel do Estado na sociedade contemporânea e sobre a distribuição de poder entre grupos sociais" (Ham \& Hill, 1993, p. 229). Tal levantamento pode-se dar por meio da exploração de três diferentes níveis de análise: (i) no funcionamento da estrutura administrativa, (ii) no processo de decisão e (iii) nas relações entre Estado e sociedade (Dagnino, Gomes, Costa, Stefanuto \& Meneguel, 2002). Para este autor, esses níveis indicam como se dão as relações políticas entre os atores envolvidos e que podem ser caracterizados conforme a síntese exposta no Quadro 1, abaixo.

Quadro 01. Níveis de Análise de Política

\begin{tabular}{|c|c|c|}
\hline $\begin{array}{l}\text { 10 Nível: Do funcionamento da } \\
\text { estrutura administrativa } \\
\text { (institucional) }\end{array}$ & $\begin{array}{l}\text { 20 Nível: Do processo de } \\
\text { decisão }\end{array}$ & $\begin{array}{l}\text { 30 Nível: Das relações entre } \\
\text { Estado e sociedade }\end{array}$ \\
\hline $\begin{array}{l}\text { Nesse nível, a análise está } \\
\text { focada no processo de decisão } \\
\text { no interior das organizações e } \\
\text { nas relações entre elas. }\end{array}$ & $\begin{array}{l}\text { Aqui ocorre a manifestação dos } \\
\text { interesses dos grupos políticos } \\
\text { que influenciam no conteúdo } \\
\text { das decisões tomadas - a } \\
\text { agenda passa a entrar no jogo } \\
\text { da relação de poder. }\end{array}$ & $\begin{array}{l}\text { Este é o nível da estrutura de } \\
\text { poder e das regras de sua } \\
\text { formação - trata da função das } \\
\text { agências estatais que, em } \\
\text { sociedades } \\
\text { avançadas, é o que assegura o } \\
\text { processo de acumulação de } \\
\text { capital e a sua legitimação } \\
\text { perante a sociedade. }\end{array}$ \\
\hline $\begin{array}{l}\text { Aqui, busca-se identificar as } \\
\text { instituições públicas com ela } \\
\text { envolvidas e os atores mais } \\
\text { evidentes nessa relação. }\end{array}$ & $\begin{array}{l}\text { Neste nível, busca-se explicar o } \\
\text { funcionamento da instituição e } \\
\text { as características da política. } \\
\text { Assim, devem-se pesquisar as } \\
\text { relações que se estabelecem } \\
\text { entre esses atores-chave } \\
\text { (internos) e grupos externos, } \\
\text { bem como as relações de } \\
\text { poder, coalizões de interesse, } \\
\text { formação de grupos (de } \\
\text { pressão, cooptação, } \\
\text { subordinação etc.) }\end{array}$ & $\begin{array}{l}\text { Esse nível permite entender, } \\
\text { mediante o conhecimento do } \\
\text { modo de produção capitalista, } \\
\text { por que as relações se } \\
\text { estabelecem entre as várias } \\
\text { porções do Estado e destas com } \\
\text { a sociedade. }\end{array}$ \\
\hline $\begin{array}{l}\text { É o nível da aparência ou } \\
\text { superficial }\end{array}$ & $\begin{array}{l}\text { É o nível dos interesses dos } \\
\text { atores }\end{array}$ & $\begin{array}{l}\text { É o que se pode denominar nível } \\
\text { da essência ou estrutural }\end{array}$ \\
\hline
\end{tabular}

Fonte: Síntese elaborada conforme caracterizações realizadas por Dagnino, Renato et al. (2002, p. 9-10).

Segundo Dagnino et al. (2002), é mediante o trânsito entre esses níveis que "é possível conhecer o comportamento da 'comunidade política' presente numa área qualquer de política pública, e desta maneira chegar a identificar as características mais essenciais de uma política" (Dagnino et al., 2002, p. 9). No primeiro nível, segundo o mesmo autor, a análise se dá em duas etapas: 
(a) primeiramente, identificam-se as organizações (instituições públicas) envolvidas na política e os atores de maior evidência;

(b) em seguida, identificam-se as relações institucionais que elas e seus respectivos atoreschave mantêm entre si.

No segundo nível, o objetivo é conhecer os interesses dos atores. Assim, torna-se imprescindível, de acordo com Dagnino et al. (2002), explicar o funcionamento das instituições e as características da política, o que pode se dar, por exemplo, por meio do exame das relações de poder, das coalizões de interesse, formação de grupos de pressão ou da cooptação.

Finalmente, no terceiro nível, como esclarece o autor, o objetivo é entender por que as relações que se estabelecem entre as várias porções do Estado e destas com a sociedade são como são. Para Dagnino et al. (2002, p. 9), "é através do estabelecimento de relações entre a situação específica que está sendo analisada ao que tipicamente tende a ocorrer no capitalismo avançado (ou periférico, no caso latino-americano) que se pode chegar a entender a essência" dessas relações.

A importância do estudo dessas relações, pelo analista político, se justifica em função dos reflexos que as ações estatais têm na vida das pessoas e da sociedade como um todo. Seja no que tange aos serviços públicos (educação, saúde, aposentadoria, seguro desemprego, habitação), seja na intervenção econômica (nas indústrias, nos tributos, nas empresas). A regulação estatal pode se dar, ainda, numa variedade de outras atividades, em virtude da complexidade social. Assim, questões ambientais, proteção do consumidor, controle de monopólio e cartéis podem sofrer regulações estatais (Dagnino et al., 2002).

Entender os níveis de análise, as visões do Estado, bem como os modelos de tomada de decisões, é fundamental ao analista no percurso de compreender uma política e todo o sistema que a rodeia. Em seguida, apresenta-se o estudo sobre a formulação da política pública, momento para onde se voltam as atenções para a tomada de decisão, sendo ainda importante ponto de partida para se entenderem as relações de distribuição de poder entre Estado e sociedade.

\section{A FORMULAÇÃO E OS MODELOS DE TOMADA DE DECISÃO}

Uma extensa bibliografia (Jones, 1970, Meny \& Thoenig, 1992, Dye, 1984, Frey, 2000), compartilhada por Serafim e Dias (2012), divide o ciclo da política em cinco momentos sucessivos, interligados e dinâmicos: 1 . identificação de problemas; 2 . conformação da agenda; 3 . formulação; 4. implementação e; 5 . avaliação da política.

Resumidamente, os autores caracterizam os três primeiros momentos da seguinte forma: (i) identificação de um problema - onde ocorre o reconhecimento do problema pelos atores envolvidos e posteriormente sua incorporação na agenda; (ii) conformação da agenda - no qual se dá a priorização de problemas e assuntos a serem trabalhados num governo e onde pode ocorrer a interferência de atores, como o legislativo, o governo, a administração pública, grupos de 
interesses, partidos políticos e o público em geral; (iii) formulação - neste, os fazedores da política materializam as fases anteriores através da elaboração da política pública.

Durante a implementação da política pública (4o momento), busca-se transformar o que foi planejado em resultados que atinjam as metas traçadas, ou, como descreve Araújo e Rodrigues (2017, p. 19), é a etapa "relativa aos processos de aprovisionamento de recursos institucionais, organizacionais, burocráticos e financeiros para a concretização das medidas de política". A avaliação (50 momento), por sua vez, serve de instrumento para revisar ou auferir o andamento ou os resultados da política pública em pauta. Esta fase poderá acontecer tanto no início, quanto durante ou após a implementação da política.

Diferentemente dos autores citados acima, Dagnino et al. (2002) exploram o ciclo da política, para fins de análise, em três momentos distintos: formulação (ou decisório), implementação e avaliação de políticas. Segundo o autor, a política é primeiramente formulada, ou seja,

[...] concebida no âmbito de um processo decisório pelos "tomadores de decisão" que pode ser democrático e participativo ou autoritário e "de gabinete"; de "baixo para cima" ou de "cima para baixo"; de tipo racional e planejado ou incremental e mediante o ajuste mútuo entre os atores intervenientes; com ou sem manipulação e controle da agenda dos atores com maior poder; detalhadamente definida ou deixada propositadamente incompleta para "ver se cola" e como é que fica "na prática" (Dagnino et al., 2002, p. 22).

É no estágio da formulação que se dá, segundo Howlett, Ramesh e Perl (2013, p. 123), o "processo de criação de opções sobre o que fazer a respeito de um problema público, fazendo-se "a identificação, o refinamento e a formalização das opções políticas que poderão ajudar a resolver as questões e os problemas reconhecidos no estágio da montagem da agenda".

Após a formulação, segue-se a implementação. Nesta fase, a da implementação, os órgãos e mecanismos estatais exercem sua discricionariedade adaptando a política formulada "à realidade da relação Estado-sociedade e das regras de formação do poder econômico e político que estas impõem ao jogo entre os atores sociais" (Dagnino et al., 2002, p. 22). Para Howlett, Ramesh e Perl (2013, p. 179) a implementação representaria "o esforço, os conhecimentos e os recursos empregados para traduzir as decisões políticas em ações".

Na última fase, a da avaliação,

[...] os resultados - entendidos como produtos e metas definidos e esperados num âmbito mais restrito - e impactos - entendidos como produtos sobre um contexto mais amplo e muitas vezes não esperados ou desejados - decorrentes de sua Implementação são comparados com o planejado (Dagnino et al., 2002, p. 22).

A avaliação, então, segundo Howlett, Ramesh e Perl (2013, p. 199), refere-se "ao estágio do processo em que se determina como uma política de fato está funcionando na prática", avaliando os meios que são empregados e os objetivos atingidos. A avaliação permite à administração

gerar informações úteis para futuras Políticas Públicas; prestar contas de seus atos; justificar as ações e explicar as decisões; corrigir e prevenir falhas; responder se os recursos, que são escassos, estão produzindo os resultados esperados e da forma mais eficiente possível; Identificar as barreiras que impedem o sucesso de um programa; 
promover o diálogo entre os vários atores individuais e coletivos envolvidos; fomentar a coordenação e a cooperação entre esses atores (Sebrae, 2008, p. 18).

Mas, é no momento da formulação que se voltam as atenções para a tomada de decisão de analistas, fazedores de política ou dos dirigentes públicos. Por isso, essa fase é de grande relevância para se medir o grau de objetividade e racionalidade que deve ser dado à delimitação dos objetivos e das estratégias da política pública que esteja em pauta. Isto porque se coloca em debate a relação entre o modelo das decisões que são tomadas e como se dá a distribuição de poder na sociedade.

Adicionalmente, é a partir do conhecimento, tanto do modelo de decisão da política pública investigada quanto da estrutura de poder envolvida em sua formulação, que se escolhe a metodologia de pesquisa que irá ser adotada numa investigação nesse nível da política.

Assim, considerando a "tomada de decisões", duas escolas, segundo Ham e Hill (1993), tratam do tema: uma concentrada na relação entre a tomada de decisão e o poder, e outra que cuida da relação entre a tomada de decisão e a racionalidade. Quanto à relação com o poder, os autores revelam as seguintes observações:

i. O enfoque na tomada de decisão é apenas um ponto de partida para se compreenderem as relações de poder;

ii. A análise das não-tomadas de decisões (que podem tomar a forma de decisões) também é importante para suplementar o estudo da relação entre poder e tomada de decisão;

iii. O poder pode modelar a preferência das pessoas (terceira dimensão do poder), podendo criar, inclusive, um falso consenso sobre normas e metas, conforme o grupo dominante.

Todavia, o entendimento sobre a relação entre tomada de decisão e a racionalidade é feito com base no debate entre o modelo racional e o processo incremental. Para Ham e Hill (1993), o modelo racional e o incremental são modelos de tomada de decisão inertes na estrutura de poder da sociedade capitalista.

O primeiro modelo, o da racionalidade, está associado a uma postura normativa; busca-se a obtenção do resultado, a escolha das melhores possibilidades disponíveis que alcançarão as metas traçadas e desejadas. Este modelo é chamado racional "no sentido de prescrever procedimentos para tomada de decisão que, teoricamente, levarão toda vez à escolha dos meios mais eficientes possíveis para atingir os objetivos de uma política" (Howlett, Ramesh \& Perl, 2013, p. 162).

Não obstante a positividade de suas intenções, esse modelo apresenta, segundo Simon (1945, p. 1 apud Ham \& Hill, 1993, p. 112), diversos problemas; dentre eles, destacamos: (a) dificuldade em identificar os valores e objetivos a serem usados no processo de tomada de decisão; (b) as metas traçadas sofrem influências discricionárias dos indivíduos e grupos que irão implementá-las; (c) há uma diversidade de alternativas para tomada de decisões e, em virtude da 
própria racionalidade humana, torna-se quase impossível conhecer as consequências de tantas alternativas; (d) dificuldade em separar fatos de valores e meios de fins.

Contudo, esse modelo apresenta indicadores bem definidos, os quais são importantes durante o momento da avaliação. Isto permite que se possa verificar se as metas foram atingidas, bem como se os resultados e impactos foram os esperados quando da implementação.

Já o modelo incremental está associado a uma postura descritiva de análise de política, considerando os interesses e ajustes políticos existentes na sociedade. Neste modelo (método de ramos), lançado por Lindblom (1959), citado por Ham e Hill (1993), analisam-se, desde o início, todas as situações existentes e que, posteriormente, serão modificadas incrementalmente por meio de comparações sucessivas limitadas. Na análise de Ham e Hill (1993, p. 119), esse modelo faz com que o tomador de decisões chegue às suas decisões "comparando políticas específicas segundo o grau em que estas levam ao cumprimento dos objetivos". Para os autores, o tomador de decisões decide se prossegue ou muda a direção da política conforme a avaliação que faz das consequências das ações que pretende tomar.

Segundo Dagnino et al. (2002), no modelo incremental, o processo decisório se efetiva pela negociação e barganha e sem planejamento. Neste caso,

[...] a formulação tem como resultado um "consenso" de caráter freqüentemente ilusório e precário, posto que baseado em mecanismos de manipulação de interesses (segunda e terceira faces do poder) que constringem a agenda de decisão a assuntos "seguros" e conduzem a situações de não-tomada de decisão que costumam favorecer as elites de poder (Dagnino et al., 2002, p. 32).

Assim, decorrente desse tipo de formulação, fatalmente se terá uma implementação desprovida de conflitos e planos concretos, cujo critério avaliativo do resultado será: "o bom é o possível" ou o "bom é o que satisfaz a elite" (Dagnino et al., 2002, p. 32). Consequentemente, o modelo de implementação adotado seria o chamado bottom up, visto que, nele, têm-se implementadores com grande poder decisório e discricionário durante a conformação da agenda, diferentemente do top down, onde se tem uma organização com planejamento e racionalidade na formulação da política e que busca minimizar o déficit da implementação.

Quando se adota, na formulação, o modelo incremental, não há preocupação na definição de indicadores para se medirem os resultados, os quais seriam necessários para se comparar o que foi projetado com o que se obteve como resultado da implementação. Logo, o que se obterá é uma avaliação com critérios difusos e subjetivos e que apenas buscam satisfazer os atores envolvidos.

Os modelos apresentados acima representam posições extremas sobre a tomada de decisão, mas servem de referência para formulação de outras propostas intermediárias, como as sistematizadas por Ham e Hill (1993) e por Hogwood e Gunn (1984).

O modelo de Ham e Hill (1993) aproxima-se, segundo Dagnino et al. (2002), de um modelo de racionalidade limitada, o qual apresenta, em relação aos seus elementos, as seguintes características: (i) considera os atores enredados em estruturas políticas e econômicas desiguais; (ii) os problemas têm suas definições em bases ideológicas; (iii) existe uma desinformação 
ideológica e vinculada ao poder; (iv) o tempo representa um poder limitado aos interesses dos atores; e (v) a estratégia prática tem por base a antecipação, a neutralização e a organização.

Na sistematização de Hogwood e Gunn (1984), citados também por Dagnino et al. (2002), utilizam-se três modelos no processo político decisório:

(i) modelo racional: neste modelo, a formulação é um processo essencialmente racional, onde as decisões se apoiam em passos sistematizados e cujos problemas são entendidos como "técnicos" (e não políticos), o ambiente é consensual e o processo fica em permanente controle;

(ii) modelo (burocrático) incremental: a formulação é vista como um processo político, em que os atores influenciam com suas percepções e interesses e tem-se a política como resultado de uma permanente barganha num ambiente em conflito;

(iii) modelo do processo organizacional: as decisões e ações são tomadas como resultado de uma escolha racional, com base em rotinas e procedimentos-padrão sistemática e previamente definidos.

Aliás, este último modelo, do processo organizacional, nos remete à importância do estudo das organizações, pois representa outro ponto de fundamental importância no processo de Análise de Política.

\subsection{Papel das Organizações na Formulação da Política Pública}

As organizações representam o local onde se dá o processo decisório e são os principais responsáveis pela implementação e pela avaliação de suas políticas. Por isso, o poder discricionário, nelas existente, exerce também um certo poder decisório durante o processo da política, tanto na formulação quanto na implementação.

Pode-se mesmo dizer, explica Elmore (1978), citado por Ham e Hill (1993, p. 157), que "somente através do entendimento de como funcionam tais organizações é que se pode compreender como as políticas são lapidadas em seu processo de implementação".

Assim, Elmore (1978 apud Ham \& Hill, 1993) apresenta uma classificação dos modelos de organização, tomando como referência o momento da implementação, seja como um (I) desenvolvimento organizacional, (II) um processo de conflito e barganha, (III) um sistema de gerenciamento ou (IV) um processo burocrático. O autor toma esses quatro tipos de organizações relacionando-as a quatro categorias de análise (Princípio Central, Distribuição de Poder, Processo de Formulação de Políticas e Processo de Implementação propriamente dito). Abaixo, apresentamos, resumidamente, por meio dos Quadros 02 e 03, as características dos tipos de organizações, conforme contribuições de Elmore (1978), trazidas por Dagnino et al. (2002).

Quadro 02. Características dos tipos de organização (I e II).

\begin{tabular}{|l|lc|l|l|}
\hline & $\begin{array}{l}\text { I } \\
\text { desenvolvimento organizacional }\end{array}$ & $\begin{array}{l}\text { II - Implementação como um } \\
\text { processo de conflito de barganha }\end{array}$ \\
\hline
\end{tabular}




\begin{tabular}{|l|l|l|}
\hline Princípio central & $\begin{array}{l}\text { Participação e compromisso dentro da } \\
\text { organização. }\end{array}$ & $\begin{array}{l}\text { Competição por vantagens relativas } \\
\text { no exercício do poder e na alocação } \\
\text { de recursos escassos. }\end{array}$ \\
\hline Distribuição de poder & $\begin{array}{l}\text { Ocorre distribuição da capacidade de } \\
\text { decisão entre todos os níveis da } \\
\text { organização. }\end{array}$ & $\begin{array}{l}\text { Determinada conhecimento, controle de recursos } \\
\text { materiais e capacidade de mobilizar } \\
\text { apoios externos. }\end{array}$ \\
\hline Formulação & $\begin{array}{l}\text { Consiste na construção de consensos } \\
\text { e sólido relacionamento interpessoal } \\
\text { entre os membros do grupo, com } \\
\text { metas compartilhadas, comunicação } \\
\text { aberta, confiança e apoio recíprocos. }\end{array}$ & $\begin{array}{l}\text { organização, na busca de alocação de } \\
\text { no decursos. } \\
\text { renterior e entre unidades da }\end{array}$ \\
\hline Implementação & $\begin{array}{l}\text { Consiste na construção de consensos } \\
\text { e acomodação entre fazedores de } \\
\text { política e implementadores. }\end{array}$ & $\begin{array}{l}\text { Consiste numa complexa série de } \\
\text { decisões negociadas refletindo as } \\
\text { preferências e recursos dos atores. }\end{array}$ \\
\hline
\end{tabular}

Fonte: Dagnino et al. (2002), segundo contribuições de Elmore (1978).

Quadro 03. Características dos tipos de organização (III e IV).

\begin{tabular}{|l|l|l|}
\hline & $\begin{array}{l}\text { III - Implementação como um } \\
\text { sistema de gerenciamento }\end{array}$ & $\begin{array}{l}\text { IV Implementação como um } \\
\text { processo burocrático }\end{array}$ \\
\hline Princípio central & $\begin{array}{l}\text {-maximizadoras de valores; } \\
\text {-racionalidade: metas. }\end{array}$ & $\begin{array}{l}\text { discricionariedade dos funcionários } \\
\text { estabelecendo rotinas. }\end{array}$ \\
\hline Distribuição de poder & $\begin{array}{l}\text {-controle hierárquico; } \\
\text {-top down. }\end{array}$ & $\begin{array}{l}\text { fragmentado entre subunidades } \\
\text { especializadas. }\end{array}$ \\
\hline Formulação & $\begin{array}{l}\text { encontrar o ótimo teórico e } \\
\text { mantê-lo. }\end{array}$ & $\begin{array}{l}\text { Controle da discricionariedade para } \\
\text { alterar incrementalmente as rotinas. } \\
\text { a valores e metas. }\end{array}$ \\
\hline Implementação & $\begin{array}{l}\text { identificação dos polos de poder para } \\
\text { coibi-los e possibilitar a mudança. }\end{array}$ \\
\hline
\end{tabular}

Fonte: Dagnino et al. (2002) ), segundo contribuições de Elmore (1978).

Os Quadros 2 e 3, apresentados acima, reforçam a importância de delimitar a organização na qual a política está sendo desenvolvida. Afinal, como já descrito, ela representa o local onde se dá o processo decisório, além de ter responsabilidade tanto na implementação quanto na avaliação de suas políticas. Logo, entender o funcionamento da organização em que se vai realizar a pesquisa é fundamental para a compreensão de como se dá o processo de formulação e implementação da política pública.

\section{CONCLUSÃO}

No presente texto, foi possível abordar temas inerentes ao interesse do analista de políticas públicas, notadamente aquele que tem como foco, principalmente, o estudo do seu processo de formulação. Para isto, realizou-se uma breve revista nas contribuições de autores inseridos no debate sobre Análise de Políticas públicas.

Inicialmente, expôs-se a compreensão de que, na formulação de políticas públicas, tem-se a identificação de um problema e sua conformação na agenda, onde atores, como o legislativo, o governo, a administração pública, grupos de interesses, partidos políticos e o público em geral, 
possivelmente poderão intervir na materialização da política pública em pauta. Ou seja, tanto o Estado como as classes sociais e a sociedade civil têm capacidade de intervenção na agenda política, visto a existência de conflitos de interesses nessas relações.

Assim, determinada classe, em conflito de interesse com outra, procura impedir que a oponente conforme seus interesses por meio das políticas públicas. Por isso, a política pública, desde sua elaboração até a sua implementação, é resultado de um jogo de forças no âmbito das relações de poder. Um poder que permite influenciar uma tomada de decisão e, inclusive, conformar as preferências das pessoas, criando um falso consenso sobre normas e metas.

Aliás, a temática sobre a tomada de decisão foi outro ponto importante tratado neste texto. Sobre ela, abordou-se a relação entre tomada de decisão e poder, notadamente sobre o debate entre racionalismo e incrementalismo, onde, segundo os autores Ham e Hill (1993), o primeiro está ligado ao aspecto normativo, na busca de resultados com base nas melhores possibilidades para se atingirem as metas objetivadas. Porém, associado a uma postura descritiva, tem-se o incrementalismo, que leva em conta os interesses e ajustes políticos existentes. São modelos a serem detectados e/ou observados pelo analista.

Entender a relação de poder pode possibilitar uma melhora no processo de formulação de políticas. Isto é possível por meio da Análise de Política, pois ela permite compreender melhor o comportamento dos atores sociais e o porquê e para quem determinada política foi elaborada. Para isto, o analista precisa levantar informações sobre o funcionamento da estrutura administrativa do Estado, sobre o processo de decisão, bem como a respeito das relações entre Estado e sociedade.

Por último, abordamos o papel das organizações na formulação da política, onde se destacou sua importância como local de processo decisório e de compreensão do ciclo da política ou de parte dela.

Assim, este artigo buscou explorar aspectos essenciais para se verificar o processo de construção da política pública, bem como a forma como isso ocorre e por que determinada política entra na agenda pública, destacando-se "um estudo da elaboração das políticas", onde as atenções se voltam à fase da formulação da política, segundo a classificação de Ham e Hill (1993).

\section{REFERÊNCIAS}

Araújo, L., \& Rodrigues, M. (2017). Modelos de Análise das Políticas Públicas. Sociologia, Problemas e Práticas, 83, 11-35.

Battini, O. \& Costa, L. C. da. Estado e políticas públicas: contexto sócio-histórico e assistência social. In: Battini, O. (org.). (2007), SUAS: Sistema Único de Assistência Social em debate. São Paulo: Veras; Curitiba, PR: CIPEC.

Boneti, Lindomar Wessler. (2007). Políticas públicas por dentro. Ijuí: Ed. Unijuí.

Dagnino, R., Gomes, E., Costa, G., Stefanuto, G. \& Meneguel, S. (2002). Gestão Estratégica da Inovação: metodologias para análise e implementação. Taubaté: Editora Cabral Universitária. 
Dias, Reinaldo \& Matos, Fernanda. (2012). Políticas Públicas: Princípios, Propósitos e Processos. São Paulo: Atlas, 2012.

Ham, Cristopher \& Hill, Michael. (1993). O processo de elaboração de políticas no Estado capitalista moderno (R. Amorim \& R. Dagnino, Trad.). Adaptação e revisão: Renato Dagnino. Campinas-SP: Editora da Unicamp.

Howlett, Michael; Ramesh, M. \& Perl, Anthony. (2013). Política Pública: seus ciclos e subsistemas: uma abordagem integral. Rio de Janeiro: Elsevier, 2013.

Rua, Maria das Graças. (1997). Análise de Políticas Públicas: conceitos básicos. Textos elaborados para o Curso de Formação para a carreira de Especialista em Políticas Públicas e Gestão Governamental. Brasília: ENAP/Ministério do Planejamento.

Rua, Maria das Graças. Políticas públicas (3a ed.) - Florianópolis : Departamento de Ciências da Administração / UFSC; [Brasília]: CAPES : UAB, 2014.

Rua, Maria das Graças \& Romanini, Roberta. Para Aprender Políticas Públicas: Conceitos e Teorias (Vol. 1). Instituto de Gestão Economia e Políticas Públicas. 2013. Recuperado de http://igepp.com.br/uploads/ebook/ebookpara_aprender_politicas_publicas-2013.pdf.

Serviço Brasileiro de Apoio às Micro e Pequenas Empresas/Sebrae. (2008). Políticas Públicas: conceitos e práticas. Belo Horizonte: Sebrae/MG. Recuperado de http://www.mp.ce.gov.br/nespeciais/promulher/manuais/MANUAL\%20DE\%20POLITICAS\%20 P\%C3\%9ABLICAS.pdf

Serafim, Milena Pavan \& Dias, Rafael de Brito. (2012). Análise de Política: uma revisão da literatura (Vol. 3). Cadernos Gestão Social, Salvador. 